\title{
Complete resolution of idiopathic pulmonary arterial hypertension following chemotherapy
}

\begin{abstract}
To the Editor:
Idiopathic pulmonary arterial hypertension (IPAH) is a rare, chronically progressive disease associated with high mortality. Despite remarkable achievements in treatment, prognosis remains poor with a survival rate of $\sim 60 \% 3$ years after diagnosis [1]. The clinical course of the disease (short survival and no cure), as well as its pathophysiological aspects, reveals analogies between IPAH and neoplastic diseases [2]. Abnormalities of pulmonary vasomotor tone only partly explain the mechanism of IPAH and more irrevocable changes, such as resistance to apoptotic signals of pulmonary arterial endothelial cells, may lead to abnormal angioproliferation and an increase in pulmonary vascular resistance [3].
\end{abstract}

We report on a 37-year-old female who presented to our pulmonary arterial hypertension (PAH) referral centre (University Medical Centre Hamburg-Eppendorf, Hamburg, Germany) with severe exercise intolerance in 2000. Her past medical history, drug history and laboratory examinations, including serology for HIV and autoimmune diseases, were unremarkable. Parenchymal lung disease, hepatosplenomegaly or adenopathy were not present on the computed tomography (CT) scan at this time. Right heart catheterisation demonstrated severe pre-capillary pulmonary hypertension, with a mean pulmonary artery pressure (mPAP) of $65 \mathrm{mmHg}$, right atrial pressure of $8 \mathrm{mmHg}$, pulmonary arterial wedge pressure of $6 \mathrm{mmHg}$, pulmonary vascular resistance of $863 \mathrm{dyn} \cdot \mathrm{s}^{-1} \cdot \mathrm{cm}^{-5}$, cardiac index of $3.01 \mathrm{~L} \cdot \mathrm{min}^{-1} \cdot \mathrm{m}^{-2}$ and pulmonary arterial oxygen saturation of $70 \%$. The patient did not respond to an inhaled vasodilatator during diagnostic catheterisation. A full diagnostic work-up, including ventilation/perfusion scanning and pulmonary angiography, ruled out other aetiologies, such as chronic thromboembolic disease, pulmonary veno-occlusive disease (PVOD) or polyneuropathy, organomegaly, endocrinopathy, monoclonal plasma cell disorder and skin changes (POEMS) syndrome. IPAH was diagnosed according to the current guidelines [4]. Inhaled iloprost (10 $\mu \mathrm{g}$ six times per day), phenoprocoumon (adapted to an international normalised ratio of 2-3) and diltiazem hydrochloride (90 $\mathrm{mg}$ three times per day) were commenced. However, therapeutic efficiency remained poor (fig. 1).

In 2003, the patient was admitted to our hospital (University Medical Centre Hamburg-Eppendorf, Hamburg, Germany) with abdominal pain and fatigue. Laboratory examination showed elevated serum lactate dehydrogenase of $301 \mathrm{U} \cdot \mathrm{L}^{-1}$. CT scan revealed severe splenomegaly and enlarged abdominal lymph nodes. In order to treat the severe symptoms and to obtain lymph node specimens, splenectomy was performed. Histology showed follicular structures of centroblasts and centrocytes showing strong expression of CD20 and MIB-1, as well as focal expression of Bcl-2 and CD10. Pathological examination of bone marrow revealed no manifestation of lymphoma or evidence for a myeloproliferative disorder. Follicular B-cell non-Hodgkin's lymphoma World Health Organization grade 3A, in stage IIs was diagnosed. Six cycles of chemotherapy with cyclophosamide $\left(750 \mathrm{mg} \cdot \mathrm{m}^{-2}\right.$, day 1$)$, doxorubicin $\left(50 \mathrm{mg} \cdot \mathrm{m}^{-2}\right.$, day 1$)$, vincristine (1.4 $\mathrm{mg} \cdot \mathrm{m}^{-2}$, day 1$)$, etoposide $\left(100 \mathrm{mg} \cdot \mathrm{m}^{-2}\right.$, days $\left.1-3\right)$ and prednisolone (100 $\mathrm{mg}$ absolute, days $\left.1-5\right)$ were administered and a radiological partial remission was achieved. Due to early progression, 4 months later salvage chemotherapy with three cycles of doxorubicin $\left(10 \mathrm{mg} \cdot \mathrm{m}^{-2}\right.$, days $\left.1-4\right)$, methylprednisolone (500 mg absolute, days $1-5$ ), cytarabine $\left(2000 \mathrm{mg} \cdot \mathrm{m}^{-2}\right.$, days $\left.1-5\right)$, cisplatin $\left(25 \mathrm{mg} \cdot \mathrm{m}^{-2}\right.$, days $\left.1-4\right)$ and rituximab $\left(1500 \mathrm{mg} \cdot \mathrm{m}^{-2}\right.$, day 1$)$ were performed leading to a complete remission, in which the patient remains until today.

Following the first course of chemotherapy, right ventricular systolic pressure only improved slightly (74 mmHg compared with $68 \mathrm{mmHg}$ ). Most interestingly, haemodynamic parameters persistently improved after the second course of chemotherapy (fig. 1). In 2012, the patient was weaned off inhaled iloprost, phenoprocoumon and diltiazem and remained stable thereafter. Right heart catheterisation 3 and 15 months after termination of this therapy demonstrated no evidence of disease with an mPAP of 12 and $17 \mathrm{mmHg}$, respectively. 


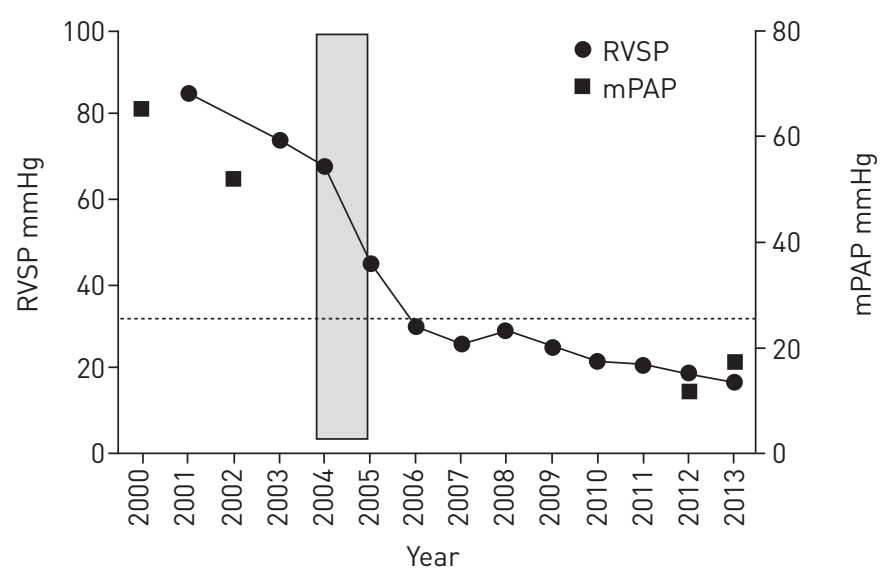

FIGURE 1 Time course of haemodynamic parameters. Right ventricular systolic pressure (RVSP) as measured by echocardiography and invasively assessed mean pulmonary artery pressure (mPAP). The shaded rectangle marks the time period of chemotherapeutic treatment (December 2003 to November 2004) and the horizontal dotted line marks the diagnostic threshold of mPAP at $25 \mathrm{mmHg}$.

Development of pulmonary hypertension $(\mathrm{PH})$ in patients with neoplastic diseases has been reported to be related to various pathomechanisms. PH may occur due to tumour-related thrombotic or nonthrombotic pulmonary embolism (group IV), or in the presence of chronic myeloproliferative disorders or tumoural obstruction of pulmonary arteries (group V) [4]. Chronic myeloproliferative disorders are a heterogeneous group of diseases associated with the development of pre-capillary PH mimicking PAH [5]. Several reported cases revealed various pathogenic mechanisms implicated in the development of $\mathrm{PH}$, such as drug- or stem cell transplantation-related PVOD, portal hypertension, splenectomy, extramedullary haematopoiesis or pulmonary leukaemic infiltration [5]. Furthermore, increased levels of circulating megakaryocytes and thrombocytosis, which can be found in patients with myeloproliferative disorders, might cause pulmonary capillary obstruction and microthrombosis [5]. Interestingly, one patient with $\mathrm{PH}$ associated with myeloid metaplasia with concomitant thrombocytosis has been reported; correction of thrombocytes by hydroxyurea led to improvement of $\mathrm{PH}$ in this patient [6]. Generally, however, $\mathrm{PH}$ developed in advanced stages of myeloproliferative disorders and chemotherapeutic treatment did not affect the course of $\mathrm{PH}$ [5]. Regarding extramedullary lymphoproliferative diseases, four cases of pulmonary intravasal lymphoma mimicking PAH have been reported [7]. However, these cases showed either abnormal radiological or laboratory findings at the time of PH diagnosis. Furthermore, tumour-related PH may also develop from heart and lung diseases due to paraneoplastic mechanisms or therapy (group II or III). With underlying neoplastic disease, development of PAH alongside PVOD has also been associated with administration of anti-neoplastic agents (group I). A well-recognised example documents treatment with the tyrosine kinase inhibitor dasatinib in patients with chronic myeloid leukaemia, which may cause development of PAH in rare cases [8].

The unique observation in the presented case is the normalisation of haemodynamic, PAH-defining parameters following cytotoxic treatment. This raises the question whether cytotoxic treatment might have had therapeutic effects in this patient. Chemotherapeutic treatment might diminish proliferation of endothelial cells, fibroblasts and smooth muscle cells, as high proliferative activity is present in pulmonary vascular arteries of patients with $\mathrm{PAH}$ [9]. Furthermore, myelotoxic therapy might eliminate haematopoietic cells and alter the levels of lineage-specific transcription factors within the haematopoietic milieu, potentially leading to a reduction of a PAH-driving multipotent myeloid cell lineage. These cells not only seem to cause PAH, as demonstrated by AsOsInGH et al. [10], who showed the development of a PAHlike vascular disease in immunodeficient mice after transplantation of bone marrow-derived CD $133^{+}$cells from $\mathrm{PAH}$ patients, but may also maintain $\mathrm{PAH}$, as indicated by higher levels of circulating bone marrowderived $\mathrm{CD}_{133^{+}}$cells in PAH patients [11]. Indeed, it has been shown that cytotoxic therapy decreased the levels of circulating $\mathrm{CD} 133^{+}$progenitor cells in lymphoma patients [12].

The second course of chemotherapy for B-cell non-Hodgkin's lymphoma in the presented case included the administration of the anti-CD20 antibody rituximab. Treatment with rituximab has been reported to improve haemodynamic parameters in two cases of $\mathrm{PAH}$ associated with systemic lupus erythematosus and adult-onset Still's disease [13, 14]. Furthermore, pre-clinically, development of severe allergy-related 
pulmonary angio-obilterative lesions induced by ovalbumin immunisation in combination with vascular endothelial growth factor blockade can be suppressed by depletion of B-lymphocytes [15]. However, an effect of rituximab on the course of disease in IPAH has not been shown and the pathogenic role of B-lymphocytes in IPAH is unclear.

The presented case raises the question whether cytotoxic treatment might have therapeutic effects in IPAH. It will be of great interest to elucidate the potential link between dysfunctional haematopoietic cells and cytotoxic treatment in patients with IPAH. However, this case represents a unique observation and should not be generalised. The possibility of an early manifestation of follicular lymphoma, which could have been occult at the time of IPAH diagnosis, cannot definitely be ruled out and more evidence will be needed before such a therapeutic approach should be utilised clinically.

0 @ERSpublications

Can systemic chemotherapy be beneficial in idiopathic pulmonary arterial hypertension? http://ow/ly/tH7z1

Lars Harbaum ${ }^{1}$, Jan K. Hennigs ${ }^{1,2}$, Hans J. Baumann ${ }^{1}$, Carsten Bokemeyer ${ }^{1}$, Horst Olschewski ${ }^{3}$ and Hans Klose ${ }^{1}$ ${ }^{1}$ II. Dept of Internal Medicine - Oncology, Haematology, BMT with Section Pneumology, University Medical Centre Hamburg-Eppendorf, Hamburg, Germany. ${ }^{2}$ The Vera Moulton Wall Centre for Pulmonary Vascular Disease, Stanford University, School of Medicine, Stanford, CA, USA. ${ }^{3}$ Division of Pulmonology, Medical University Graz, Graz, Austria.

Correspondence: L. Harbaum, II. Dept of Internal Medicine - Oncology, Haematology, BMT with Section Pneumology, University Medical Centre Hamburg-Eppendorf, Martinistr. 52, 20246 Hamburg, Germany. E-mail: 1.harbaum@uke.de

Received: Oct 242013 | Accepted after revision: Nov 202013

Conflict of interest: None declared.

Acknowledgements: The authors are very thankful to H.J. Bogaard (Dept of Pulmonary Medicine, VU University Medical Center, Amsterdam, the Netherlands), who critically reviewed the manuscript.

\section{References}

1 Humbert M, Sitbon O, Chaouat A, et al. Survival in patients with idiopathic, familial, and anorexigen-associated pulmonary arterial hypertension in the modern management era. Circulation 2010; 122: 156-163.

2 Rai PR, Cool CD, King JA, et al. The cancer paradigm of severe pulmonary arterial hypertension. Am J Respir Crit Care Med 2008; 178: 558-564.

3 Rabinovitch M. Molecular pathogenesis of pulmonary arterial hypertension. J Clin Invest 2012; 122: 4306-4313.

4 Simonneau G, Robbins IM, Beghetti M, et al. Updated clinical classification of pulmonary hypertension. J Am Coll Cardiol 2009; 54: Suppl. 1, S43-S54.

5 Adir Y, Humbert M. Pulmonary hypertension in patients with chronic myeloproliferative disorders. Eur Respir J 2010; 35: 1396-1406.

6 Marvin KS, Spellberg RD. Pulmonary hypertension secondary to thrombocytosis in a patient with myeloid metaplasia. Chest 1993; 103: 642-644.

7 Kotake T, Kosugi S, Takimoto T, et al. Intravascular large B-cell lymphoma presenting pulmonary arterial hypertension as an initial manifestation. Intern Med 2010; 49: 51-54.

8 Hennigs JK, Keller G, Baumann HJ, et al. Multi tyrosine kinase inhibitor dasatinib as novel cause of severe precapillary pulmonary hypertension? BMC Pulm Med 2011; 11: 30.

9 Jonigk D, Golpon H, Bockmeyer CL, et al. Plexiform lesions in pulmonary arterial hypertension composition, architecture, and microenvironment. Am J Pathol 2011; 179: 167-179.

10 Asosingh K, Farha S, Lichtin A, et al. Pulmonary vascular disease in mice xenografted with human BM progenitors from patients with pulmonary arterial hypertension. Blood 2012; 120: 1218-1227.

11 Farha S, Asosingh K, Xu W, et al. Hypoxia-inducible factors in human pulmonary arterial hypertension: a link to the intrinsic myeloid abnormalities. Blood 2011; 117: 3485-3493.

12 Igreja C, Courinha M, Cachaco AS, et al. Characterization and clinical relevance of circulating and biopsy-derived endothelial progenitor cells in lymphoma patients. Haematologica 2007; 92: 469-477.

13 Hennigan S, Channick RN, Silverman GJ. Rituximab treatment of pulmonary arterial hypertension associated with systemic lupus erythematosus: a case report. Lupus 2008; 17: 754-756.

14 Padilla-Ibarra J, Sanchez-Ortiz A, Sandoval-Castro C, et al. Rituximab treatment for pulmonary arterial hypertension in adult-onset Still's disease. Clin Exp Rheumatol 2013; 31: 657-658.

15 Mizuno S, Farkas L, Al Husseini A, et al. Severe pulmonary arterial hypertension induced by SU5416 and ovalbumin immunization. Am J Respir Cell Mol Biol 2012; 47: 679-687. 